\title{
In Memory of Jacob Schwartz
}

Sal Anastasio, Coordinating Editor

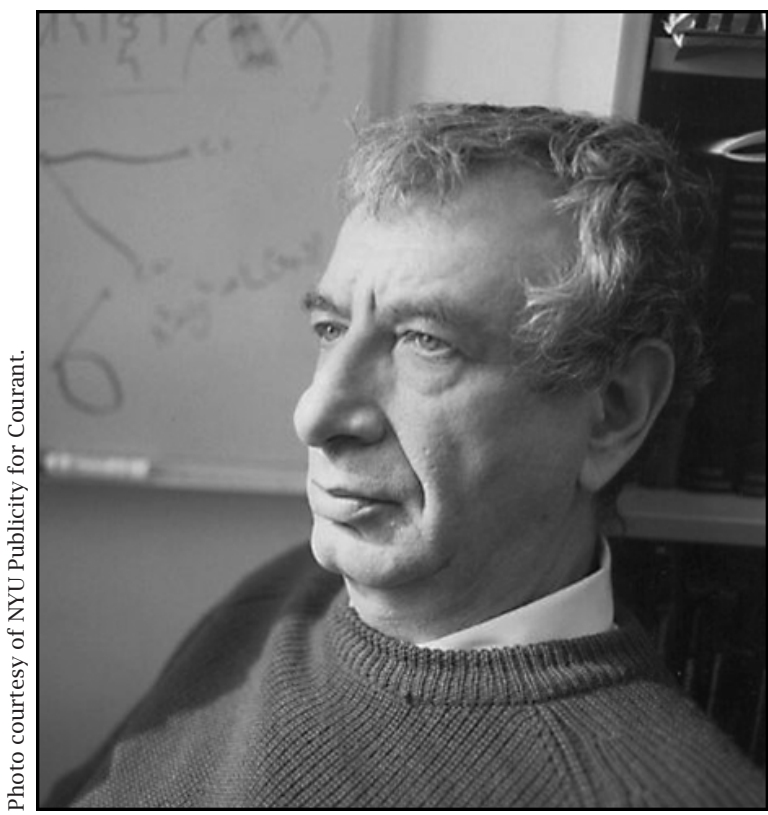

Jack Schwartz.

A few months after Jack Schwartz's death on March 2, 2009, a memorial gathering was held for him at the Courant Institute of New York University, his home base for almost fifty years. The well-planned program included a few piano pieces and almost a dozen speakers, each of whom had collaborated with Jack in one or more of his many activities.

Those present would have heard the speakers talk about:

Sal Anastasio is professor emeritus of mathematics, SUNYNew Paltz. His email address is anastass@hawkmai1. newpaltz. edu.

Personal and family photos of J. Schwartz provided by and used with permission of the Schwartz family.

DOI: http://dx.doi.org/10.1090/noti1246
- The outstanding contributions Jack had made to many fields and his ability to enter a field new to him, master it, make significant contributions, and move on.

-Jack's exceptional kindness and generosity. Eugenio Omodeo spoke of his "deep empathy with others"; Edmond Schonberg said that "his generosity had changed the lives of many;" and his sister, Judith, said that, to Jack, "acts of exceptional kindness were perfectly routine" and that his "stunning generosity...did not look for thanks" and "he was puzzled and even annoyed when they came."

-Finally, and in a lighter vein, Jack's addiction to particular Chinese restaurants whose quality ranged from, at best, "mediocre," to, at worst, "loathsome."

Jacob Theodore Schwartz was born on January 9, 1930, in the Bronx, New York City, of immigrant parents: his father, Ignatz, from Hungary, and his mother, Hedwig, from Germany. At every level of his life, Jack was precocious. As a child he was an omnivorous reader. He attended Stuyvesant, a high school for gifted students. At age nineteen he graduated from the City College of New York (a producer of many Nobel Prize winners and frequently called, at that time, "the poor man's Harvard"). While there, he studied with E. L. Post. His friend and colleague Martin Davis recalls that Jack interpreted one of Post's remarks as expressing a need for a proof that all recursive functions are Turing computable, and Jack sent such a proof to Post. The letter we have reproduced was Post's response to Jack. It shows that Post recognized Jack's exceptional ability and that he was correct in his prediction of Jack's future.

Jack began graduate study at Yale and completed his $\mathrm{PhD}$ at age twenty-two. He then began to collaborate with his thesis advisor, Nelson Dunford, on what was to become the monumental three-volume Linear Operators, known simply to mathematicians as "Dunford-Schwartz." Jack left Yale for the 
Courant Institute in 1957 and continued there until his retirement in 2005. In the mid-1960s he became interested in computer science, eventually being instrumental in founding the computer science department at Courant in 1969 and chairing the department. In addition to developing the programming language SETL, he made major contributions to computer architecture, parallel computation, and compiler optimization.

In the early 1980s Jack became interested in robotics and founded the robotics laboratory at New York University. His work there consisted not only of theoretical aspects but of such practical issues as robot programming and machine manufacturing. Toward the end of his life he became interested in the field of multimedia. His coworker in the field was Ken Perlin. Ken said that "Jack brought the same high level of engagement, original thinking, and intellectual rigor to this topic that he had brought to all his previous work. Jack saw, before nearly anyone else, the shift in the US from a manufacturing economy to an information economy. He realized that this would bring about a profound cultural change in which computers and interactivity would become an integral part of both the creation and the consumption of media. As usual, Jack was right."

This sketch of his achievements is fleshed out in the following articles and recollections. For a more complete biography, we refer the reader to the memoir written by Martin Davis and Edmond Schonberg for the National Academy of Sciences: www. nason7ine.org/member-directory/ deceased-members/50702.htm1.

For more thorough essays on his work from the time of his entry into the field of computer science, we refer the reader to From Linear Operators to Computational Biology, M. Davis and E. Schonberg, eds., Springer, 2013.

\section{Ronald G. Douglas and Ciprian Foias}

\section{Contributions to Operator Theory}

Jacob (Jack) T. Schwartz was one of the very few contemporary mathematicians who had solid knowledge of many fields of modern and classical mathematics, to which he made outstanding contributions from "abstract mathematics" all the way to "concrete applications" in "applied mathematics." This organic connection between "abstract

Ronald G. Douglas is Distinguished Professor of Mathematics, Texas A\&M University. His email address is rdoug7as@math . tamu .edu .

Ciprian Foias is Distinguished Professor of Mathematics, Texas A\&M University. His email address is foias@math.tamu.edu.

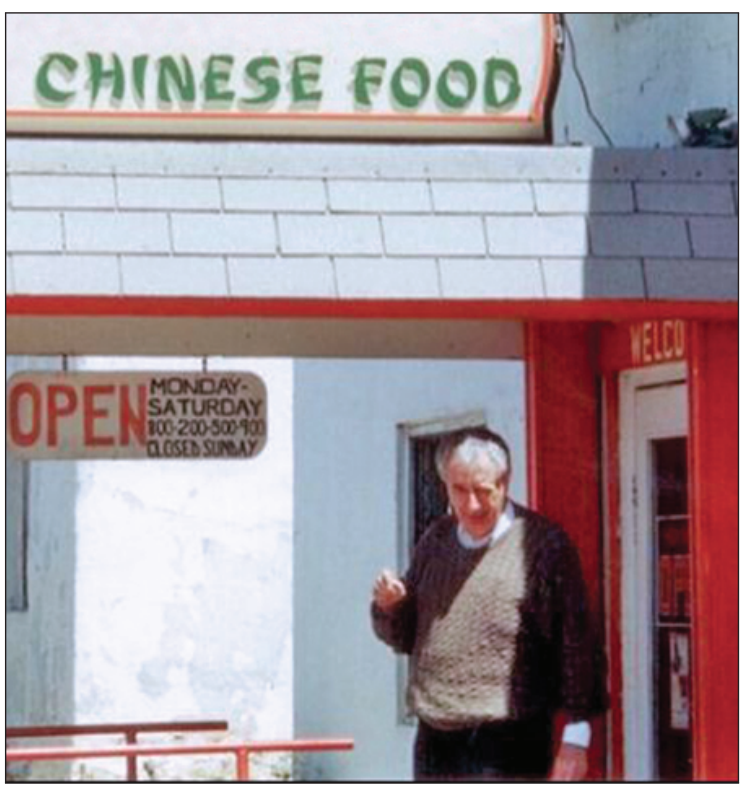

Jack at a favorite Chinese food restaurant, Los Angeles, California, 1989. Photo by Diana Schwartz.

theory" and "concrete applications" is present in many of Jack's contributions to operator theory, as well as in the monumental encyclopedic three volume treatise Linear Operators, by N. Dunford and J. T. Schwartz, a project seemingly initiated by Dunford, in which several of his doctoral students (including Jack) were involved. Jack, with his great mathematical power and working stamina, became the main driving force behind the project and, in particular, directed the choice and presentation of the rich mathematical content of the treatise. Moreover, the books present a detailed history of the development of operator theory up to that time, in which, as the authors indicate, they were assisted by W. G. Bade and R. G. Battle.

A good illustration of Jack's approach to linear operator theory-namely, it should play the role of a catalyst for understanding the structure and the properties of the linear maps arising in other branches of mathematical study-is the extended presentation in Volume II of Linear Operators of the boundary value problems for finite systems of ordinary differential equations using operator theory (that is, the use of semigroups of linear operators as the catalyst). This is also illustrated by the extension in Volume III of Dunford's spectral theory from bounded operators to unbounded ones, as well as by Jack's studies of the ("full" or "partial") preservation of the "good" spectral features of an operator under certain perturbations which occur in applications. Many of Jack's results in this direction were first published in Volume III of Linear Operators and constitute the most 
original part of the whole treatise. It is this part which, due to the progress made since then in "functional analysis", provides inspiring new paradigms and opportunities for "pure and applied operator theory."

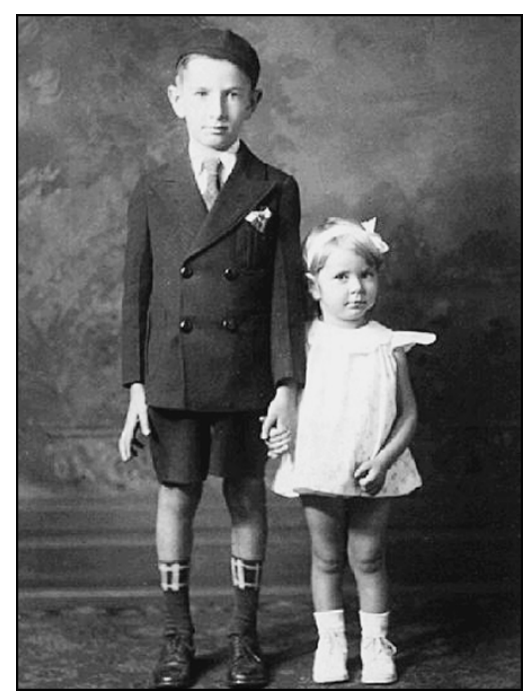

Jack, age five, with sister, Judith Dunford, 1935.

On a more personal side, Jack was a very generous mathematician. As an example, the second author of this eulogical article is very indebted to him. While Jack was still working on Volume II of Linear Operators, he encouraged I. Colojoara and the second author to write a monograph on their slightly more abstract spectral decomposition approach. After they sent Jack their manuscript, the "mail connection" concerning that work was interrupted by the local authorities (who else?), so, in particular, they never got the galley proofs. Nevertheless, Jack rewrote parts of their (rather clumsy) introduction and published the work in his Gordon \& Breach Mathematics and Applications series.

\section{Wai-Mee Ching}

\section{$W^{*}$-algebras}

John von Neumann initiated the study of operator algebras on Hilbert space, now called von Neumann algebras or $W^{*}$-algebras, in 1929 [1], and starting from 1936 F. Murray and von Neumann wrote a series of papers entitled "On rings of operators" [2], [3], [4] to systematically study these algebras partially intended to lay an algebraic generalization of the quantum mechanical formalism. Let $\mathrm{H}$ be a separable Hilbert space, $B(H)$ be the self-adjoint *-algebra of all bounded linear operators on $H$, with $T \rightarrow T^{*}$ (the adjoint operator of $T$ ) as the *-involution. A self-adjoint subalgebra $A$ of $B(H)$ is a $W^{*}$-algebra if it is weakly closed. Let $A^{\prime}$ be the set of all operators in $B(H)$ which commute with all operators in $A$, the commutant of $A$. Then $A$ is a $W^{*}$-algebra iff $A=A^{\prime \prime}$; this is called the double commutant theorem [2]. $A \cap A^{\prime}=C(A)$

Wai-Mee Ching is a retired professor of computer science from the IBM Thomas J. Watson Research Center. His email address is waimeeching@gmai1.com. is called the center of $A$. Let $M$ be a $\mu$-finite measure space, $L_{2}(M)$ the Hilbert space of squareintegrable functions $g$ on $M$. Then $L_{\infty}(M)$, the set of all essentially bounded $\mu$-measurable functions $f$ corresponding to $m_{f}: g(x) \rightarrow f(x) g(x)$, is a commutative $W^{*}$-algebra on $L_{2}(M)$, and the center of $L_{\infty}(M)$ is equal to itself. On the other end of the spectrum, a $W^{*}$-algebra $A$ is called a factor if $c(A)$ is just $C$, the field of complex numbers, i.e., scalar multiples of the identity operator $I$. An operator in $A$ is a projection if $E=E^{*}=E E$. Two projections in $A$ are equivalent, $E \sim F$, if there is a partial isometry $u$ in $A$ such that $u u^{*}=E, u^{*} u=F$. This defines a partial order among projections of $A$, and this partial order is a linear order if $A$ is a factor. A projection $E$ is finite if there is no projection $F \sim E$ with $0<F<E$; $E$ is minimal if simply no such $F$ exists. Murray and von Neumann proved [2] that there are three and only three different types of factors:

Type I: has minimal projections, $I_{n}, n=1,2, \ldots$, the $n \times n$ matrix algebra, and $I^{\infty}, B(H)$ for infinite dimensional $H$;

Type II: $\mathrm{II}_{1}$ if the identity operator I is finite, $I I_{\infty}$ if the identity operator I is infinite;

Type III: all projections are infinite.

In the final paper [5] of the rings of operators series, von Neumann proved that every $W^{*}$-algebra $A$ can be uniquely expressed, up to isomorphism, as a direct integral of factors over a measure space arising from a measure space $M$ associated with $c(A)$. This can be regarded as an infinite-dimensional extension of the classical Wedderburn Structure Theorem for semisimple finite-dimensional rings. Thus, the classification of $W^{*}$-algebras has been reduced to the classification of factors. While type I factors are familiar objects, the discovery of type II and type III factors was quite unexpected. There are several ways to construct factors of type $\mathrm{II}_{1}$. For example, let $G$ be a countable discrete group such that the set $C_{h}=\left\{g h g^{-1} \mid g \in G\right\}$ is infinite for all $h$ in $G$ other than the identity element; we call it an ICC (infinite conjugate class) group. Let $l_{2}(G)$ be the Hilbert space of all square-summable functions on $G$ and $A(G)$ be the $W^{*}$-algebra generated by the unitary translation operators $U_{g}$ on $l_{2}(G), g \in G$ :

$$
f(h) \rightarrow\left(U_{g} f\right)(h)=f(h g) .
$$

Then $A(G)$ is a factor of type $\mathrm{II}_{1}$. Now let $\prod$ be the group of all finite permutations on $\mathbb{Z}$, the set of integers; then $A(\Pi)$ is a factor of type $\mathrm{II}_{1}$. A factor is called hyperfinite if it is the weak closure of an increasing sequence of finite dimensional subalgebras. Let $M_{2} \subset M_{4} \subset M_{8} \subset \cdots$ be the increasing sequence of finite-dimensional algebras of operators represented by repeating $2^{k}$ by $2^{k}$ matrices along the diagonal; we can see that the resulting closure of this sequence is also a 
hyperfinite factor of type $\mathrm{II}_{1}$. There is another way to construct (hyperfinite) factors of type $\mathrm{II}_{1}$ (and type III) by a group of automorphisms acting on an abelian $W^{*}$-algebra called the cross-product. In [4] Murray and von Neumann proved that all hyperfinite factors of type $\mathrm{II}_{1}$ are isomorphic to each other. Furthermore, they showed that $A\left(F_{2}\right)$, the group algebra associated with the free group $F_{2}$ of two generators, is not hyperfinite. This is achieved by introducing property $\lceil$ : for any $\epsilon>0$ and any $T_{1}, T_{2}, \ldots, T_{m}$ in $A$ there is a unitary operator $U$ in $A$ such that $\operatorname{tr}(U)=0$ and $\left|U T_{i}-T_{i} U\right|_{2}<\epsilon, i=1,2, \ldots, m$, and showing that $A\left(\prod\right)$ has property 「 while $A\left(F_{2}\right)$ does not.

After this discovery of a pair of nonisomorphic factors of type $\mathrm{II}_{1}$ in 1943, a natural question in the structural classification of factors is: are there other nonisomorphic nonhyperfinite factors of type $\mathrm{II}_{1}$ ? An obvious candidate is $A\left(F_{3}\right)$, the $W^{*}$-algebra associated with the free group of three generators which is also nonhyperfinite. Is $A\left(F_{2}\right)$ isomorphic to $A\left(F_{3}\right)$ ? This turns out to be a very hard problem on which we'll comment later.

In 1963 Jack [6] introduced property $P$ : a $W^{*}$. algebra $A$ on a Hilbert space $H$ has property $P$ if for every $T \in B(H)$, the convex hull of $\left\{U T U^{*} \mid U \in A\right\}$ contains an element of $A^{\prime}$, the commutant of $A$. He showed that the hyperfinite factor $A\left(\prod\right)$ has property $P$ while $A\left(F_{2}\right)$ and $A\left(\prod \times F_{2}\right)$, the factor associated with the direct group product of $\Pi$ and $F_{2}$, do not have property $P$, but $A\left(\Pi \times F_{2}\right)$ has property $\lceil$. Hence, twenty years after knowing there was a pair of nonisomorphic factors of type $\mathrm{II}_{1}$, it was shown that there were three nonisomorphic factors of type $\mathrm{II}_{1}$. Jack wrote a book on $W^{*}$-algebras in 1967 [31], which for a while was the only comprehensive treatment on $W^{*}$-algebras (von Neumann algebras). In 1968 W. Ching [7] discovered the fourth nonisomorphic factor of type $\mathrm{II}_{1}$ by introducing property $C: W^{*}$-algebra $A$ has property $C$ if, for each sequence $U_{k}(k=1,2, \ldots)$ of unitary operators in $A$ with the property that strong $\lim U_{k}^{*} T U_{k}=T$ for each $T \in A$ there exists a sequence of mutually commuting operators $V_{k}$ $(k=1,2, \ldots)$ in $A$ such that strong $\lim \left(U_{k}-V_{k}\right)=0$ and exhibiting a nonhyperfinite factor $A(H F)$, where $H F$ is a group constructed from a crossproduct of a group of automorphisms acting on a free group of infinite generators with the free group, such that $A(H F)$ has property $C$ while $A\left(F_{2}\right)$ and $A\left(\Pi \times F_{2}\right)$ do not have property $C$. Shortly after, Sakai [8] found the fifth nonisomorphic factor of type $\mathrm{II}_{1}$ by introducing the property of being asymptotically abelian. Dixmier and Lance [9] found the sixth and seventh nonisomorphic factors of type $\mathrm{II}_{1}$, and Zeller-Meier [11] found the eighth and ninth nonisomorphic factors of type $\mathrm{II}_{1}$. Finally, within about a year, McDuff found infinitely many nonisomorphic factors of type $\mathrm{II}_{1}$ [10] and a continuum of nonisomorphic factors of type $\mathrm{II}_{1}[12]$. All these results can be found in the book The Structure of Factors [13] by Sal Anastasio and Paul Willig, two of Jack's PhD students.

Whether $A\left(F_{2}\right)$ is isomorphic to $A\left(F_{3}\right)$ remains an open problem. In retrospect, the significance of Jack's contribution in the search for nonisomorphic factors is not just that he introduced property $P$, which was later found to be equivalent to hyperfiniteness by Connes [14], to enable the finding of a third nonisomorphic factor of type $\mathrm{II}_{1}$ but that he shifted attention from the much harder problem concerning free group algebras (which he may well have attempted) to a more fruitful direction. Nevertheless, there are some interesting and surprising results in attacking the free group front. In $1973 \mathrm{~W}$. Ching [15] introduced a new method for constructing factors, called the free product of von Neumann algebras, in order to find a factor of type $\mathrm{II}_{1}$ without property 「similar to $A\left(F_{2}\right)$, and this was subsequently extended to the free product of $C^{*}$-algebras (a $C^{*}$-algebra is a norm closed Banach algebra which has a selfadjoint ${ }^{*}$-involution; $W^{*}$-algebras form a subset of $C^{*}$-algebras) by Avizour [16]. This early work was later developed into free probability theory (a noncommutative version of classical probability theory) by Dan Voiculescu [17]. Using Voiculescu's free probability theory, L. Ge [18] proved that $A\left(F_{n}\right)$ for $n>1$ cannot be the tensor product of two factors of type $\mathrm{II}_{1}$; i.e., in a sense they are prime factors. Note that $A\left(\prod \times F_{2}\right)$ is in fact the tensor product of $A(\Pi)$ and $A\left(F_{2}\right)$. A more surprising result on the nonisomorphism of free group factors is the recent work of K. Guo and H. Huang [18]: they relate the free group factor classification problem to complex analysis and conformal geometry by constructing factors of type II arising essentially from holomorphic coverings of bounded planar domains.

On factors of type III, after von Neumann [3] in 1940 showed the existence of a factor of type III, Pukanszky [20] in 1956, with the aid of property $L$, showed a pair of nonisomorphic factors of type III. Jack in [21] showed the existence of three nonisomorphic factors of type III using property $P$. In 1967 Powers [22], using $C^{*}$-algebra techniques, proved that there exists a continuum of pairwise nonisomorphic hyperfinite factors of type III. In [7] Ching showed that there are three nonisomorphic nonhyperfinite factors of type III; and by 1969 , through the use of techniques from the type $\mathrm{II}_{1}$ case, the existence of a continuum of pairwise nonisomorphic nonhyperfinite factors of type III was established. In 1968 Araki and Woods in a paper [23] on infinite tensor products proved Powers's result using exclusively $W^{*}$-algebra techniques. 


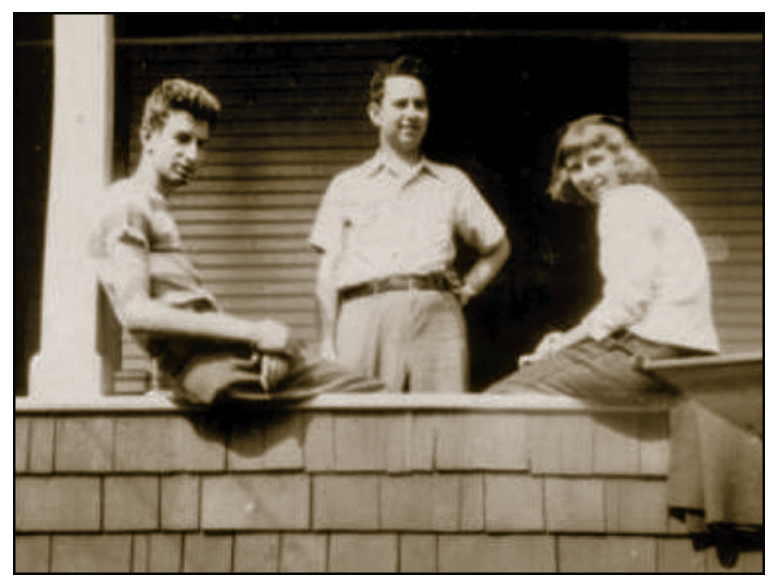

Jack, Martin Davis, and Judith Dunford, Rockaway Beach, NYC, summer 1948. Photo taken by Jack's mother, Hedwig.

Jack's reinterpretation of [23] is in [24], which can be found in the book of Anastasio and Willig [13]. Jack's elucidation [24] of Powers's result leads to the most elementary proof of the existence of a one-parameter family of mutually nonisomorphic factors of type III by Ching [25], where the infinite tensor product of $W^{*}$-algebras is not used.

Jack's mathematical prowess is also evident in his later work in computer science. His remarkable ability to absorb a complex proof and recast it in a simpler and clearer fashion enabled him to swiftly move from one discipline to another. In mathematics, expressing this simplification may only have pedagogical or aesthetic value, but in computer science it makes a huge difference between something implementable and something which never gets implemented. An example is that of interval analysis of F. Allen and J. Cocke [26] (Allen was married to Jack for many years, Cocke was a good friend and collaborator of Jack's in writing a comprehensive compiler book, and both are Turing Award recipients, the highest honor in computer science), used crucially in program optimization. Instead of step-by-step graph reduction, Tarjan [27] (another Turing Award recipient) found a fast interval finding algorithm, but it is Jack's version [28] of Tarjan's algorithm that is implemented in an APL compiler [29], where interval analysis is used in type-shape analysis, which is partly inspired by the thesis of Jack's $\mathrm{PhD}$ student [30].

\section{References}

[1] John von Neumann, Zur Algebra der Funktionaloperatoren und Theorie der normalen Operatoren, Math. Ann. 102 (1929), 370-427.

[2] F. J. Murray and John VOn Neumann, On rings of operators, Ann. Math. 37 (1936), 116-229.

[3] John Von Neumann, On rings of operators III, Ann. Math. 41 (1940), 94-161.
[4] F. J. Murray and JOHN VON NEUMANN, On rings of operators IV, Ann. Math. 44 (1943), 716-808.

[5] JOHN VON NEUMANN, On rings of operators. Reduction theory, Ann. Math. 50 (1949), 401-485.

[6] JACOB T. SchwARTz, Two finite, nonhyperfinite nonisomorphic factors, Comm. Pure Appl. Math. 16 (1963), 19-26.

[7] W.-M. ChING, Nonisomorphic nonhyperfinite factors, Canad. J. Math. 21 (1969), 1293-1308.

[8] S. SAKaI, Asymptotically abelian type $\mathrm{II}_{1}$ factors, Publ. R.I.M.S. Kyoto Univ. Ser. A 4 (1968), 299-307.

[9] J. DiXMIER and E. C. LANCE, Deux nouveaux facteurs de type $\mathrm{II}_{1}$, Invent. Math. 7 (1969), 226-234.

[10] G. ZELLER-MeIER, Deux autres facteurs de type $\mathrm{II}_{1}$, Invent. Math. 7 (1969), 235-242.

[11] D. McDufF, A countable infinity of $\mathrm{II}_{1}$ factors, Ann. Math. 90 (1969), 361-371.

[12] _ Uncountably many $\mathrm{II}_{1}$ factors, Ann. Math. 90 (1969), 372-377.

[13] S. ANASTASIO and P. WILlig, The Structure of Factors, Algorithmic Press, NY, 1974.

[14] A. Connes, Classification of injective factors, Ann. Math. 104 (1976), 73-115.

[15] W.-M. CHING, Free product of von Neumann algebras, Trans. Amer. Math. Soc. 178 (1973), 147-163.

[16] D. Avitzour, Free product of $C^{*}$-algebras, Trans. Amer. Math. Soc. 271 (1982), 423-435.

[17] D. Voiculescu, Symmetries of some reduced free product $C^{*}$-algebras, Lecture Notes in Math., 1132, Springer, 1985 , pp. 556-588.

[18] L. GE, Prime factors, Proc. Natl. Acad. Sci. USA 93 (1996), 12762-12763.

[19] K. GUO and H. HuANG, Multiplication operators defined by covering maps on Bergman space: the connection between operator theory and von Neumann algebras, J. Funct. Analysis 260 (2011), 1219-1255.

[20] L. PukAnszKy, Some examples of factors, Publ. Math. Debrecen 4 (1956), 135-156.

[21] J. T. SCHWARTZ, Nonisomorphism of a pair of factors of type III, Comm. Pure Appl. Math. 16 (1963), 111-120.

[22] R. POWERS, Representations of uniformly hyperfinite algebras and their associated von Neumann rings, Ann. Math. 86 (1967), 138-171.

[23] H. ARAKI and E. J. Woods, A classification of factors, Publ. R. I. M. S. Kyoto Univ. Ser. A 3 (1968), 51-130.

[24] J. T. SchwarTz, Recent progress in the structure theory of factors, Functional Analysis (ed. C. Wilde), Academic Press, New York, 1970, pp. 37-53.

[25] W.-M. CHING, On some nonhyperfinite factors of type III, Canad. Math. Bull. 18(5) (1975), 643-648.

[26] F. ALLEN and J. COCKE, A program data flow analysis procedure, Comm. ACM 19(3) (1976), 137-147.

[27] R. TARJAN, Testing flow-graph reducibility, J. Comput. Syst. 9 (1974), 355-365.

[28] J. T. SCHWARTZ and M. SHARIR, A Design for Optimizations of Bitvectoring Class, Courant Comp. Sci. Rep., 17, NYU, September 1979.

[29] W.-M. CHING, Program analysis and code generation in an APL/370 compiler, IBM J. Res. \& Dev. 30 (6), 594-602.

[30] A. Tennenbaum, Type determination for Very High Level Languages, Courant Comp. Sci. Rep., no. 3, NYU, 1974.

[31] J. T. SchwARTZ, $W^{*}$-algebras, Gordon \& Breach, New York, 1967. 


\section{Martin Davis}

Jack Schwartz and I were undergraduate students at City College in New York during the late 1940s, both influenced by the important logician E. L. Post and the charismatic teacher B. P. Gill. In the first of the many organizational efforts Jack was to lead, he created a committee of students to reproduce the lecture notes on real variable theory by H. F. Bohnenblust in order to supply Post with an up-to-date textbook for his course on that subject. More than half a dozen students laboriously copied the notes onto mimeograph stencils working with manual typewriters and using a stylus for mathematical symbols. Jack added his own appendix "Why Is a Topological Space?" to explain briefly the importance of abstraction in twentieth-century mathematics. During the summer of 1949, just before Jack began his graduate studies at Yale, he and I, together with my fellow graduate student at Princeton, Melvin Hausner, lived in his parents' apartment in the Bronx while they were at the beach. Jack had discovered the AMS Colloquium Series, and he was working his way through Lefschetz's Algebraic Topology and Weil's Foundations of Algebraic Geometry. It was a mathematically productive summer for the three of us.

Jack and I became colleagues when I joined the Courant Institute in 1965, where Jack had been on the faculty since the 1950s. In 1969 we were both founding members of the new computer science department at Courant, although Jack had already been working in that field for some time.

\section{Jack's Work in Economics}

I've written elsewhere [3] about how Jack's critical work on Marx's economic theories arose out of the controversies within a radical group with which we were both involved. His first toy economic models were part of his effort to convince the others of the falsity of Marx's theory of price ratios. His lectures and the remarkable book [4] that he developed from them owe more to Keynes than they do to Marx. However, his view of an economy as represented by the flow of commodities as the output of one producer becomes an input to another ultimately derives from Marx as further developed by Leontief. In the book, rigorous mathematical treatment of economic models is complemented by discussions of empirical data and historical context. Jack's Keynesian models

Martin Davis is professor emeritus of the Courant Institute. His email address is martin@eipye.com.

My thanks to Kumaraswamy Velupillai, who kindly read an early draft of this article and saved me from making a number of errors in what I wrote about economics. Obviously any errors that remain are due to me.-M.D. take the form of dynamical systems with a fixed point (he called the "Keynes point") representing an equilibrium between demand and production. The ordinary business cycle was then exhibited as a path moving around this point. From this point of view catastrophic events (like those in 1929 and 2008) on the one hand and substantial governmental stimulation of production (as occurred in the US during the Second World War) on the other are seen as shifting the Keynes point to a new equilibrium. Jack emphasized the relevance to economics of John Nash's work on $n$-person games well before this was generally realized. Jack's point of view stands in contrast to the orthodoxy of its time promulgated in Paul Samuelson's textbook that was studied by thousands of students. In this "neoclassical synthesis," an important role was played by the classical theory of prices determined by "supply and demand" as expressed in the general equilibrium models of Leon Walras. After studying Keynesian and Walrasian models separately, Jack developed a single model which incorporated both Keynesian and Walrasian phenomena and illustrated how unsatisfactory could be the real situation corresponding to a Walrasian equilibrium:

Equilibrium models...give content to the classical notion of the "invisible hand" of economics.... Enthusiasts of neoclassical policy [emphasize] the opinion that this equilibrium is...optimal. After all, at equilibrium each family maximizes its satisfaction, and each firm maximizes its profits.... As we see from the above [analysis], motion toward equilibrium may very well involve a drastic reduction of capital inventory ...in equilibrium: each family optimizes its subjective utility subject to budgetary constraints; each firm maximizes its profits subject to its capital limitations...this may mean nothing more than that each family manages as best it can subject to a severe shortage of funds, and that each firm makes the largest possible profit on the small amount of capital remaining to it....

John Nash's work showed how players in one of his games could be trapped in a situation in which a "move" that would provide general improvement if carried out by most would nevertheless prove catastrophic to any player with the courage to make that move as an individual. The Walrasian equilibrium described in the above quotation may be thought of as providing such an instance.

Regarding an economy as a gigantic structure in which commodities enter productive enterprises as inputs and emerge as outputs leads to viewing monetary phenomena as a secondary overlay

\footnotetext{
${ }^{1}[4]$, p. 230.
} 


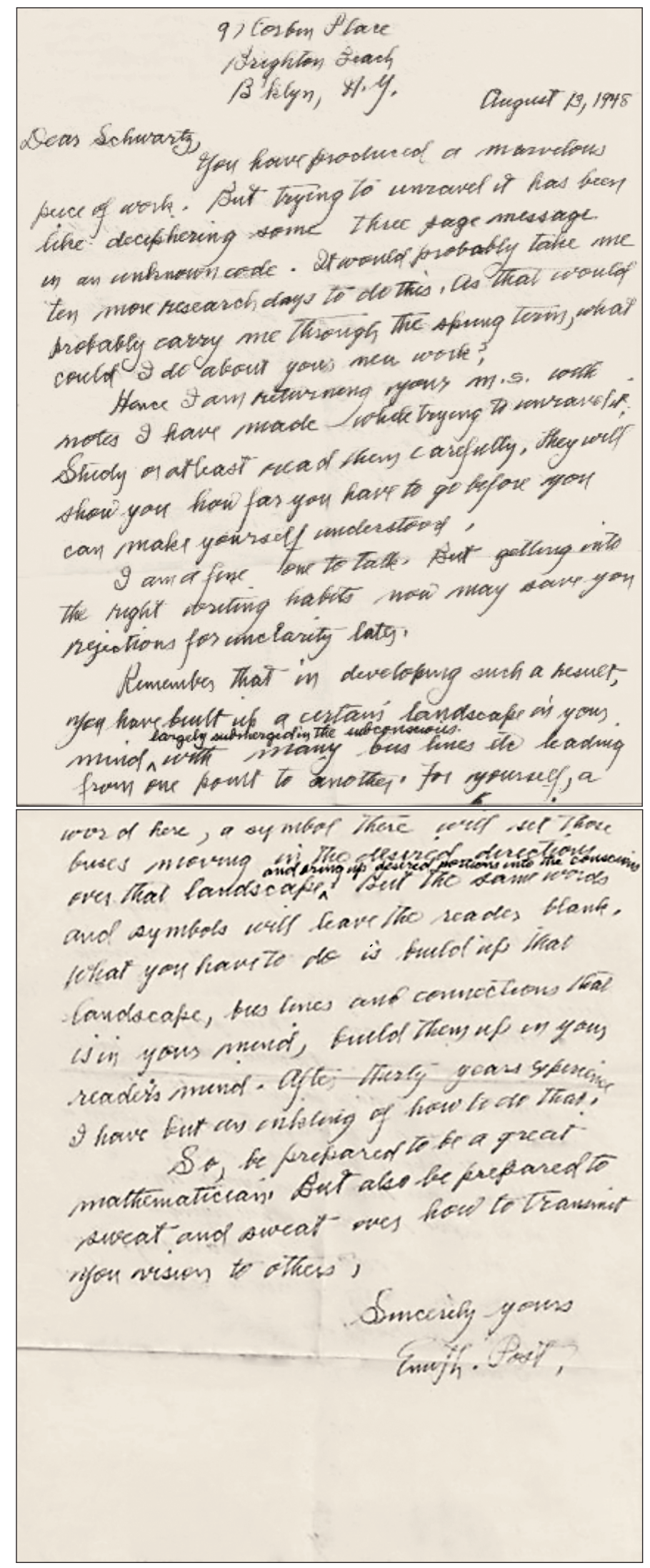

Scanned pages from a letter of Post to Jack, 1948. 


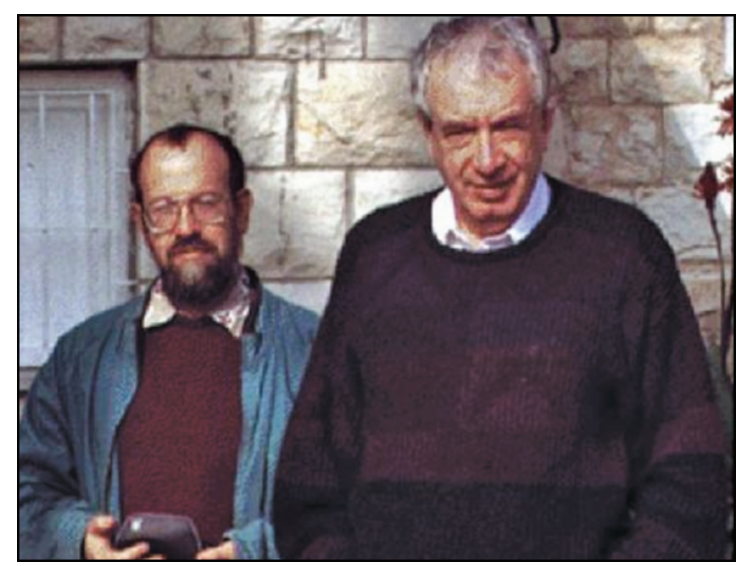

Jack and Micha, 1992, Tel Aviv University. Photo taken by Diana Schwartz.

to the underlying material reality. Indeed, Jack emphasizes that the fact that an analysis of the business cycle is possible in that context makes efforts to see the business cycle as a monetary phenomenon quite dubious. Nevertheless, he wrote the relatively brief book [5] to analyze the role that money plays. Very much in the spirit of his earlier book, the point of view is Keynesian, and the classical quantity theory of money is found seriously wanting.

\section{Mathematics in Computer Science}

From the variety of topics dealing with computer technology with which Jack engaged, there are two threads where his work led to interesting and significant mathematics. It was thinking about robotics that led Jack to consider algorithms for negotiating a terrain with obstacles, what he called the "piano movers problem." This led to a number of joint papers with Micha Sharir and with John Hopcroft. See [6] (which has references to previous work) and [7].

Jack had developed a high-level programming language he called SETL in which the underlying data objects were sets. He imagined technology to prove the correctness of programs written in such a language by augmenting it with setbased automated reasoning technology. This led to his fruitful suggestion that algorithms found by Hilbert's student Behmann could be extended to a set-theoretic context. Some of his and my students who returned to their native Italy after obtaining their doctorate at Courant developed this insight in a remarkable manner. They found that a significant part of axiomatic set theory can be developed in a decidable context. See [2] (which has many references to earlier work) and [1].

\section{References}

[1] JaCob T. Schwartz, Domenico Cantone, and EugeNIO OMODEO, Computational Logic and Set Theory: Applying Formalized Logic to Analysis, Springer, 2011.

[2] Domenico Cantone, Eugenio Omodeo, and Alberto POLICRITI, Set Theory for Computing: From Decision Procedures to Declarative Programming with Sets, Springer, 2001.

[3] MARTIN DAVIS, Jack Schwartz meets Karl Marx, From Linear Operators to Computational Biology, M. Davis and E. Schonberg, eds., Springer, 2013, pp. 23-38.

[4] Jacob T. Schwartz, Lectures on the Mathematical Method in Analytical Economics, Gordon \& Breach, New York, 1961.

[5] _ Theory of Money, Gordon \& Breach, New York 1965.

[6] JACOB T. SChWARTZ and Micha SHARIR, On the piano movers problem: IV. The case of a rod moving in three-dimensional space amidst polyhedral obstacles, Comm. Pure Appl. Math. 37 (1984), 815-848.

[7] JOHN E. HOPCROFT, JACOB T. SCHWARTZ, and Micha SHARIR, On the complexity of motion planning for multiple independent objects; PSPACE hardness of the 'Warehouseman's Problem,' Intl. J. Robotics Research 3 (1984), 76-88.

\section{Micha Sharir}

\section{Jack Schwartz and Robotics}

My encounter with Jack began in 1977 when I joined the SETL group that he was heading at the Courant Institute, working with him on compiler optimization of high-level languages. We continued our collaboration after I returned to Israel. Then, in 1981 during one of my visits to the Courant Institute, as I was sitting in Jack's office, all of a sudden Jack posed the problem of planning the motion of a line segment $e$ in the plane amid polygonal obstacles. Since the motion of $e$ has three degrees of freedom (two of translation and one of rotation), one can think of such a motion as an arc traced in the parametric 3-dimensional configuration space $C$, representing all possible placements of $e$. Each obstacle $o$ becomes a socalled expanded obstacle $K_{0}$ in $C$, which is the locus of all placements of $e$ that intersect $o$. The complement in $C$ of the union of the expanded obstacles $K_{0}$ is the free configuration space $F$, consisting of all collision-free placements of $e$. Now, given a starting position $s$ and a target position $t$ of $e$, the question becomes: Do $s$ and $t$ (as points in $C$ ) belong to the same (arcwise) connected component of $F$ ?

This formalization of the problem emerged a bit later. At the time Jack was proposing the problem, he already had some sketches of a suggested ad hoc algorithm, and in no time at all

Micha Sharir is professor of computer science, Tel Aviv University. His email address is michas@post. tau. ac. $i 1$. 
we were fully immersed in this problem. This led to our joint work on the series of "Piano Movers" papers, which laid the foundation for algorithmic motion planning. The first paper in the series [10] presented an algorithm for solving Jack's initial problem, but it was the second one [11] which has been the most influential, as it gave a general solution to the motion planning problem, using and refining techniques from real algebraic geometry. Specifically, the configuration-space formulation reviewed above applies for any moving system $B$ with $k$ degrees of freedom and for a collection of obstacles whose shapes and locations are known to the planning system. Here too one can define the (now $k$-dimensional) configuration space $C$, the expanded obstacles, and the free configuration space $F$ in complete analogy to the case of a segment. Given a start and goal placements of $B$, the question to answer is whether there exists a continuous collision-avoiding motion of $B$ from the start placement to the goal placement and, if so, to produce such a motion. Equivalently, we want to determine whether $s$ and $t$ lie in the same connected component of $F$.

Under reasonable assumptions, the expanded obstacles and the complement $F$ of their union are real semialgebraic sets, and the problem is to compute a discrete representation of the topological structure of such a set. This is a challenging mixture of algorithmic combinatorics (to handle the large number of scattered obstacles) and of computational algebra (to effectively compute the interaction between the algebraic varieties that form the boundaries of the expanded obstacles).

The algorithm that Jack developed in [11] is based on Collins's cylindrical algebraic decomposition (CAD) [3] (see also [2]) but refines it to handle the (potentially quite complicated) topology of $F$. Using and adapting a variety of tools from real algebraic geometry, the resulting algorithm is exact and takes time which is doubly exponential in $k$ but polynomial in the other parameters of the problem. Thus, for any fixed system $B$ one gets an exact polynomial-time (albeit considerably inefficient) algorithm for planning its motion amid a given collection of obstacles (again, under reasonable assumptions on the shape of the moving system and of the obstacles).

The paper [11] opened up many new research directions, and its impact is felt even today. I feel "safe" in praising that paper, because it was to a large extent Jack's creation. My role had been that of a disciple running after the master, learning a lot from him, and helping wherever I could. In retrospect, several other more efficient solutions were found later, such as the "roadmap" approach of Canny and of Basu et al. (see the comprehensive

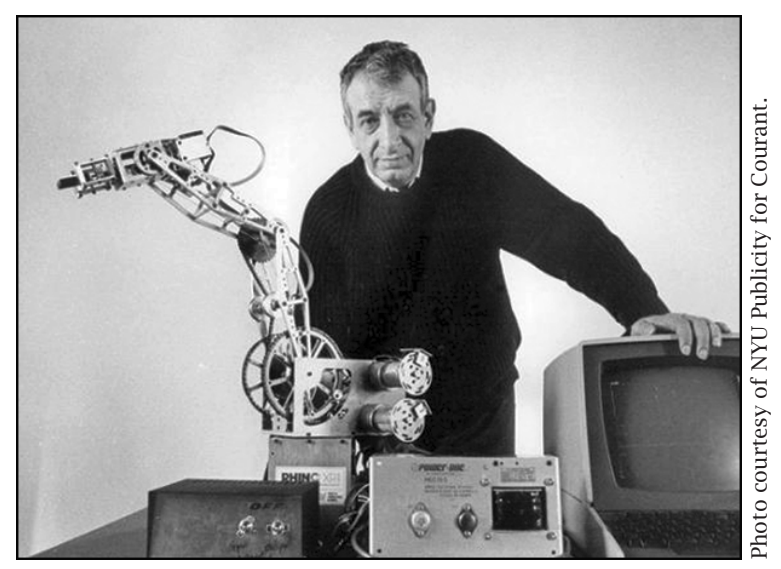

Jack and robotics.

book [2] for details), but the breakthrough was definitely Jack's.

This was only the beginning. Jack had entered the world of robotics with his usual unbounded energy, vigor, and stamina and for nearly ten years continued to lead an intensive research activity in robotics, where his mathematically oriented inquisitive mind unraveled many beautiful and difficult mathematical challenges. With the aid of a large NSF Infrastructural Grant, Jack founded a few years later the Robotics Lab at the Courant Institute, which became one of the major centers for robotics research during the 1980s. As usual, he was interested in everything: many fundamental questions in motion planning, questions related to shape and pattern recognition (for which he introduced the technique of geometric hashing, which is still used today quite effectively in the analysis of molecular structures in bioinformatics [21]), questions related to friction and grips of objects [8], [18], and many others). A large portion of this work and several other parallel developments were recorded in a book edited by John Hopcroft, Jack, and me [6] and in several surveys [13], [16], [19].

One should also note that motion planning was one of the major motivational forces that influenced the development of computational geometry, a vibrant field that was making its first steps at that time. Among the main developments resulting from this interaction were the study of arrangements of curves and surfaces, Davenport-Schinzel sequences and their geometric applications, and space-decomposition techniques; see [20] for details. This has been my main field of interest ever since. Jack dabbled a bit in this area too (see, e.g., [4], [17]) but was never really attracted to it. Towards the end of the 1980s and beginning of the 1990s, his interests shifted to other topics (ultracomputers, multimedia, logic, 
bioinformatics, and what not), and our scientific ways slowly drifted apart.

\section{References}

[1] C. M. BASTuSCHECK, E. SCHONBERG, J. T. SCHWARTZ, and M. SHARIR, Object recognition by 3-dimensional curve matching, Int. J. Intell. Control Systems 1 (1986), 105-132.

[2] S. BASU, R. POLLACK, and M.-F. RoY, Algorithms in Real Algebraic geometry, Algorithms and Computations in Mathematics, vol. 10, Springer Verlag, Berlin-Heidelberg, 2003.

[3] G. E. Collins, Quantifier elimination for real closed fields by cylindric algebraic decomposition, 2nd GI Conf., Aut. Theory and Formal Languages, SpringerVerlag, LNCS 33, Berlin, 1975, pp. 134-183.

[4] J. E. Hopcroft, J. T. SCHWARTZ, and M. SHARIR, Efficient detection of intersections among spheres, Int. J. Robotics Research 2(4) (1983), 77-80.

[5] , On the complexity of motion planning for multiple independent objects; PSPACE hardness of the 'Warehouseman's Problem,' Int. J. Robotics Research 3(4) (1984), 76-88.

[6] (eds.), Planning, Geometry, and Complexity of Robot Motion, Ablex Pub. Co., Norwood, NJ, 1987.

[7] A. Kalvin, E. Schonberg, J. T. Schwartz, and M. SHARIR, Two dimensional model based boundary matching using footprints, Int. J. Robotics Research 5(4) (1986), 38-55.

[8] B. Mishra, J. T. Schwartz, and M. Shamir, On the existence and synthesis of multifinger positive grips, Algorithmica 2 (1987), 541-558.

[9] S. Ocken, J. T. Schwartz, and M. Sharir, Precise implementation of CAD primitives using rational parametrization of standard surfaces, in Planning, $\mathrm{Ge}$ ometry, and Complexity of Robot Motion (J. Hopcroft, J. Schwartz, and M. Sharir, eds.), 1987, pp. 245-266.

[10] J. T. SCHWARTZ and M. SHARIR, On the Piano Movers' problem: I. The case of a rigid polygonal body moving amidst polygonal barriers, Comm. Pure and Appl. Math. 36 (1983), 345-398.

[11] _ On the Piano Movers' problem: II. General techniques for computing topological properties of real algebraic manifolds, Advances in Appl. Math. 4 (1983), 298-351.

[12] _ On the Piano Movers' problem: III. Coordinating the motion of several independent bodies: The special case of circular bodies moving amidst polygonal barriers, Int. J. Robotics Research 2(3) (1983), 46-75.

[13] _ Mathematical problems and training in robotics, Notices Amer. Math. Soc. 30 (1983), 478-481.

[14] _ On the Piano Movers' problem: V. The case of a rod moving in three-dimensional space amidst polyhedral obstacles, Comm. Pure Appl. Math. 37 (1984), 815-848.

[15] _ Identification of partially obscured objects in two and three dimensions by matching of noisy 'characteristic curves,' Int. J. Robotics Research 6 (2) (1987), 29-44.

[16] _ A survey of motion planning and related geometric algorithms, Artificial Intelligence 37 (1988), 157-169. (Also in Geometric Reasoning) D. Kapur and J. Mundy, eds.), M. I. T. Press, Cambridge, MA, 1989, pp. 157-169; and in Autonomous Mobile Robots, Vol. I
(S. S. Iyengar and A. Elfes, eds.), IEEE Computer Society Press, Los Alamitos, CA, 1991, pp. 365-374.

[17] _ On the two-dimensional Davenport Schinzel problem, J. Symbolic Computation 10 (1990), 371-393.

[18] _ _ Finding effective 'force targets' for twodimensional multifinger frictional grips, Algorithmica 8 (1992), 1-20.

[19] _ Algorithmic motion planning in robotics, an invited chapter, Handbook of Theoretical Computer Science, Vol. A: Algorithms and Complexity (J. Van Leeuwen, ed.), Elsevier, Amsterdam, 1990, 391-430.

[20] M. SHARIR and P. K. AgARWAL, Davenport-Schinzel Sequences and Their Geometric Applications, Cambridge University Press, New York, 1995.

[21] H. J. Wolfson and I. Rigoutsos, Geometric hashing: An overview, IEEE Computational Science and Engineering 4 (1997), 10-21.

\section{Michael Wigler}

Jack's intellectual arc took him from mathematics to computational science to biology. I had already expanded from molecular biology into quantitative genomics and had worked with Bud Mishra, one of Jack's close colleagues at Courant. Bud thought Jack and I should meet. My first impression of Jack was of someone who had overestimated the power of computation and underestimated the byzantine complexities of biological systems. Only later did I realize that Jack was hoping to be perplexed. He chose biology to help him peer into the universe, beyond the limits of pure human imagination. He was driven by curiosity, sometimes curiosity about his intellectual reach, and his method of exploration was determined by two influences.

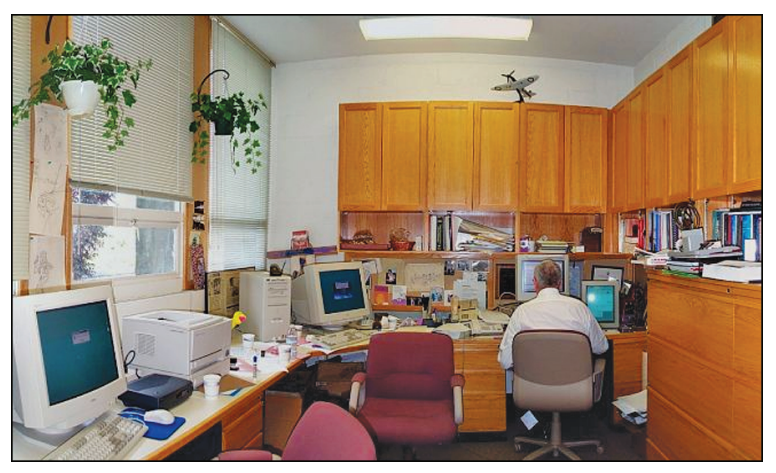

Jack at post in Cold Spring Harbor.

The first was mathematics. In Jack's view only two mathematical fields were especially "successful" in explaining the world: linear algebra and calculus. Most would agree on calculus but perhaps question linear algebra. Not Jack. I suspect that in Jack's view calculus was in fact a subfield of linear algebra on infinite-dimensional vector spaces. His mathematical world view translated to his approach

Michael Wigler is professor of genetics, Cold Spring Harbor Laboratory. His email address is wigler@csh1. edu. 
to exploring biology: span as much of the biological space as possible with a basis, a set of tools that could be combined. The second influence was computation. More so than for anyone I have ever met or read about or seen depicted, the computer was an extension of Jack's sensory and cognitive apparatus. The computer was itself a source of insights into how the cell and the brain might work.

By the time I knew him, except for Jack's collaborative work on computational logic and mathematics [1], he had stopped writing for publication, although he was active in creating websites. His biological thinking, results, and methods are not in print. I will very briefly touch upon two topics that illustrate his thinking. Reference [2] contains a more inclusive and detailed account, anecdotes, some of Jack's sayings, and links to still extant websites.

Genomics was a natural subject for Jack. DNA, the genetic material, is comprised of strings of the four nucleotide letters that are the "digitized" information repository of the cell. Jack was expert at string computation, and for this the sort was the fundamental operation. This resulted in our one joint paper [3], which introduced an important string matching algorithm into the library of genomic tools. Jack's main insights were based on higher order principles of genomic organization, and he discovered measures of evolutionary distance based on reorganization. Changes in gene order ("synteny") and gene splicing pattern are slower ticking clocks than the standard clock based on local nucleotide sequence divergence and thus might be superior for perceiving the phylogenetic tree. Jack used mitochondrial gene order to discover surprising details of the evolutionary relation between crustaceans and at the same time rediscovered the principles of homologous recombination, previously recognized and explained by the Holliday junction model.

Cognition was another biological arena that drew his attention. He mulled over everyday occurrences that usually go unobserved, such as the time needed to recover a name or to complete memories from shards, to make inferences about the information storage and processing algorithms in neurons. Behind his thinking was the unquestioned assumption that the capacity of the brain was indeed built from discrete components and that the perception of the continuity of perception that we all enjoy is in fact an illusion.

His systematic explorations of the brain were of the visual system, and here the computer was both tool and object. He was fascinated by optical illusions, which were to Jack examples of how the brain uses clues to reconstruct a reality. Because he had mastered the computing of images,

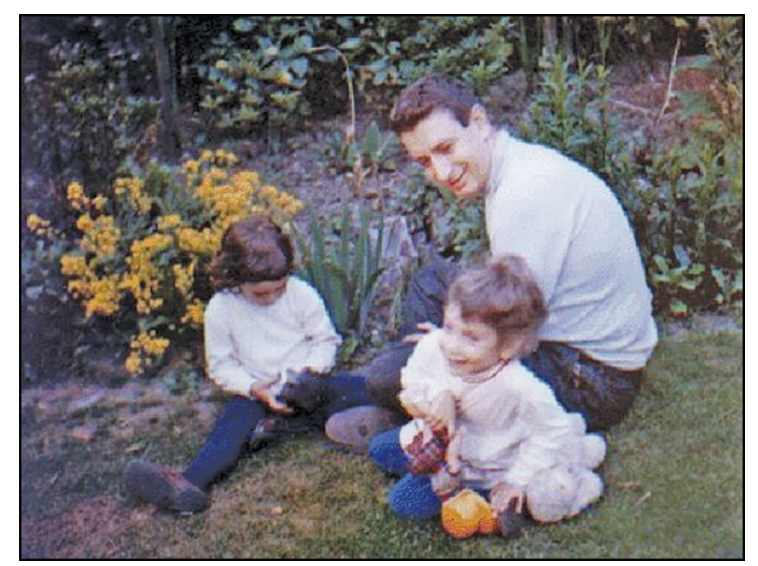

Jack and daughters, Rachel and Abby. Photo taken by Sandra Schwartz.

Jack could create endless "illusions" and vary the parameters that make an illusion "work." Then he would explore the human variability in sensitivity to visual processing clues. His favorite set of illusions was based on the perception of three dimensions, and for study of these, he extended the power of the computer monitor by donning colored glasses. Among his discoveries my favorite was that when the mind was stretched beyond its ability to interpret a computer image as arising from differential object depth, the computer image would attain a strong, almost unpleasant, metallic sheen. To me that illusion was indeed brain magic.

To his surprise and mine, there was great individual variability in the ability to interpret visual clues in an illusion, as though some people had different cognitive algorithms. These differences were as stark as the illusions that can distinguish color-blind people from people with full spectral range. Such discrete individual differences in cognitive capacity are rare and are typically genetic in etiology. Such clues could therefore be a "lead" that unravels the connections between behavior, circuitry, and genes.

Sadly, I only knew Jack for his last decade, but happily he still casts a large influence. His successful examples with computational approaches and the perception of the mathematical structure beneath the surface of biological phenomena greatly encouraged my own explorations in those directions.

\section{References}

[1] JACOB T. SChWARTZ, Domenico CANTONE, and EugeNIO G. OMODEO, Computational Logic and Set Theory, Springer-Verlag London Limited, 2011.

[2] Michael WigleR, The last ten yards, in M. Davis and E. Schonberg (eds.), From Linear Operators to Computational Biology, Essays in Memory of Jacob T. Schwartz, pp. 195-202, London: Springer-Verlag London, 2013. 
[3] J. Healy, E. Thomas, J. T. Schwartz, and M. Wigler, Annotating large genomes with exact word matches, Genome Research 13 (2003), 2306-2315.

\section{Joseph A. Fisher}

In April 1970, Jack and John Cocke of IBM Yorktown Heights wrote Programming Languages and Their Compilers: Preliminary Notes, Second Revised Version, Apri1 1970. This report gave birth to an entire field of computer science, "Compiler Optimization," and was remarkable in its completeness and, from the perspective of almost forty-five years later, its insight, thoroughness, and effect on modern processor development. It was released as a technical report by the Courant Institute and never published in any other format (it is available for download at The Computer History Museum, www.softwarepreservation.org).

Reading this report in 2013, it generally feels like something you would indeed expect to find in a museum. But not the 218 pages devoted to compiler optimization. As was typical of Jack, what emerged on those pages was the invention of a new, full-fledged field of computer science, "compiler optimization," thoroughly described. It is as if the subject had existed in the literature and practice for decades, and someone finally got around to writing an encyclopedic survey paper. But instead, little was known of this subject before 1970, and much less written. Frances Allen and Cocke had embarked on seminal work in interval analysis, and there were smatterings of techniques being developed, also largely at IBM Yorktown. David Gries's classic Compiler Construction for Digital Computers was not published until 1971 and emphasized areas other than optimization. It was not until 1977 that the "Dragon Book," Aho and Ullman's Principles of Compiler Design, finally laid out this subject again in a systematic way, repeating Cocke and Schwartz in greater detail.

The rest of the 767-page report was a thorough survey of the state of the art in compiler construction, covering such maturing topics as lexical analysis, parsing, syntactic analysis, formal language theory, and a few pieces of code generation for special-purpose languages. These were all relatively mature subjects by then, some approaching an almost ripe stage. But not so optimization: there was really nowhere to go if you were a compiler writer and wanted to understand optimization.

The general framework in the report persists to this day. Jack and Cocke covered what are still the most important topics:

Joseph A. Fisher is Senior Fellow Emeritus at Hewlett-Packard. His email address is joseph.a.fisher@gmai 1. com.
- Machine independent vs. machine specific optimizations

- Reduction in strength

- Value numbering

- Constant propagation

- Dead variable elimination

- Code motions

- Test replacement

- Loop unrolling

- Register allocation techniques

- Program rearrangement to enhance instruction-level parallelism

- Gathering operations into more complex operations

Given that so little had been published in the area, it is not possible to know who besides Jack, Cocke, and Allen might have invented some of the techniques listed. IBM Research was the industrial hotbed of compiler optimization, and with Jack's leadership, Courant quickly became the academic hotbed. Under Jack and Cocke's supervision, Ken Kennedy furthered the work in global analysis in his Courant PhD, then went off to Rice, where he led what was (and is) the most productive group in the world doing compiler backend research. Josh Fisher's work at Courant on program rearrangement to enhance instructionlevel parallelism led to the development of VLIW architectures and the invention of instruction-level parallelism as a subject rather than a smattering of techniques. And in between those two, and beyond, optimization techniques have grown, usually in ways directly traceable to Courant and to dog-eared copies of Cocke and Schwartz.

A large percentage of modern processor performance is due to the effect of compiler optimization, though, unlike the more glamorous hardware technology, it remains invisible to most people. And every performance-oriented compiler written since the report was published has used these techniques, usually in much the manner first laid out in Cocke and Schwartz.

\section{Peter D. Lax}

Jack Schwartz had the most powerful mind of anyone I knew, except for John von Neumann. These two had in common a fantastic ability to learn new subjects extremely rapidly, and both had an incredibly wide range of interest. When Jack retired from the Department of Mathematics to lead the newly created Department of Computer Science, he related to me that when he came to the Courant Institute he had decided to teach all courses listed in our bulletin and that he had carried out his plan. When I pointed out that there

Peter D. Lax is professor emeritus of the Courant Institute. His email address is 1ax@cims.nyu.edu. 


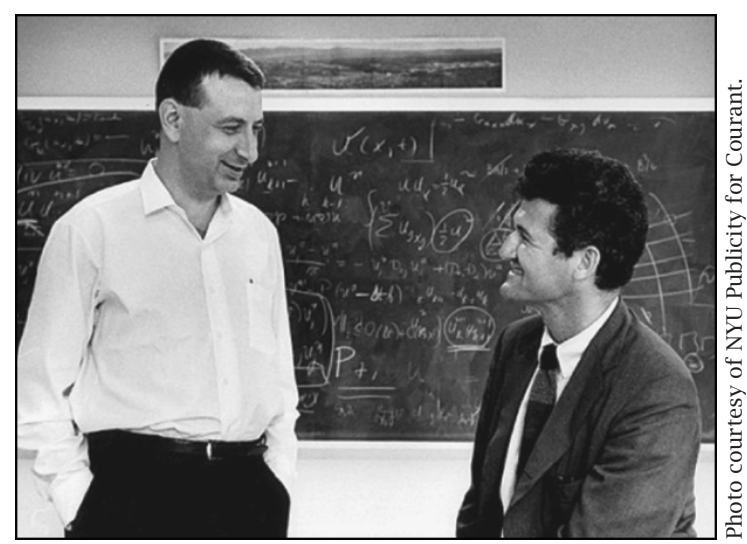

Jack and Peter Lax.

must have been some subjects about which he knew little or nothing, he replied that in those cases he took out, the summer before, the leading texts on the subject and learned it. When I asked him if there was a subject he had trouble learning, he admitted that there was, namely, fluid dynamics. "It is not a subject that can be expressed in terms of theorems and their proofs," he said.

Jack first came to the attention of the mathematical community as the coauthor of "DunfordSchwartz," an impressive exposition of functional analysis. It is much more than a compilation and organization of known material; there is much original work in it. A striking example is the theorem that the trace of a trace-class operator in Hilbert space is the sum of its eigenvalues. This theorem and its proof are presented in volume 2 , but no attribution is given to Lidskii, to whom it is due. Since "Dunford-Schwartz" is compulsive about giving references, this was mystifying. The explanation is that volume 2 came out before the publication of Lidskii's paper: Jack had proved the result independently.

Jack made valuable contributions to the theory of operator algebras, a subject founded by von Neumann and Murray. Jack described von Neumann's work as "coming repeatedly to a stone wall and crashing through it."

Jack had a delicious sense of humor. In a paper titled "The pernicious influence of mathematics on science" he starts with the observation that "computer intelligence" has three major shortcomings: single-mindedness, literal-mindedness, and simple-mindedness. He then makes the point that mathematics also has these shortcomings, although to a lesser extent. As an example he points to the claim that the Birkhoff ergodic theorem is the basis of the foundation of statistical mechanics and then neatly demolishes the claim.

As another example, Jack quotes Keynes's criticism of some mathematical economics as "... a mere concoction, as imprecise as the initial assumptions they rest on, which allow the author to lose sight of the complexities and interdependencies of the real world in a maze of pretensions and unhelpful symbols."

Hans Bethe once remarked, only half in jest, that von Neumann's brain was an upward mutation of the human brain. The same could have been said about Jack. We shall not see the like of him for a long time.

\section{Louis Nirenberg}

I first met Jack Schwartz when he and Nelson Dunford came to visit New York University for some months. They were writing their magnificent magnum opus on linear operators at the time and Jack gave a series of talks on some of the material. Everyone was bowled over by the brilliance, clarity, and depth of the lectures. Sometime after they returned to Yale I was invited to give a talk there. I spoke about my thesis, and Jack understood everything I had done immediately, before I could finish describing it. When I returned to New York I urged Courant to hire him, so I might have played a small role in Jack's coming to NYU.

Jack had an incredible mind, and he read mathematics the way most of us read fiction. Peter Lax was once visiting Stanford and went to see Jack, who had arrived the night before. Jack greeted him by saying, "Have you something to read? I've already read the corn flakes box three times." He taught an enormous variety of courses and even wrote a book on the theory of money. With all his brilliance he was always very unassuming. Our research did not overlap much, so I did not follow his work.

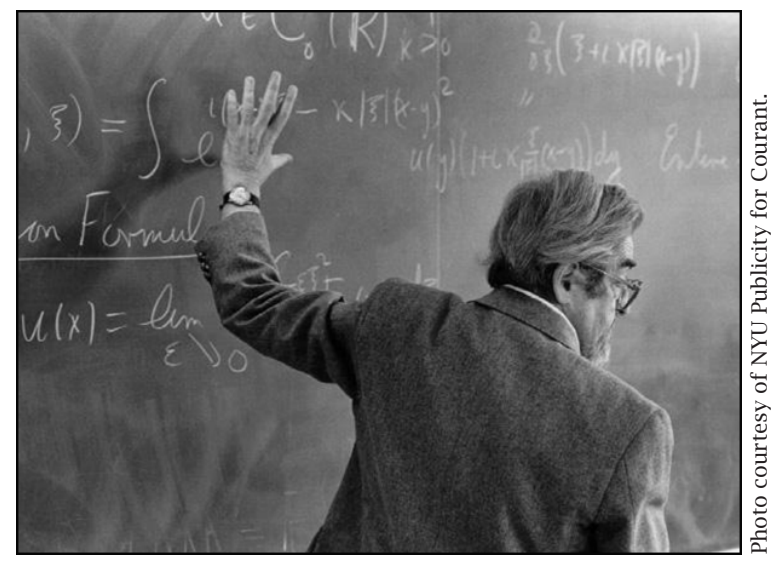

Louis Nirenberg at the blackboard.

When he left mathematics for computer science it was a great gain for computer science, but

Louis Nirenberg is professor emeritus of the Courant Institute. His email address is ni ren1@cims.nyu. edu. 
I considered it a great loss for mathematics. Afterwards we did not have so much contact, but in the last years of his life we met occasionally for lunch. He would choose the restaurant-often with undistinguished food. Well, nobody's perfect! It was always a great pleasure to meet with him. We would talk about everything under the sun. On occasion he would show me the latest addition to his collection of African sculpture. I miss him a lot.

\section{Wai-Mee Ching}

\section{Personal Recollection}

Since my thesis work in von Neumann algebras followed that of Jack's in that area, I came to know him before I left Toronto, and he was my mentor since I finished my $\mathrm{PhD}$ forty-five years ago. Jack had a decisive influence on my career. Fairly early he encouraged me to explore computer science. Later, when I began to learn compiler construction, I asked him how to get a solid grip on the subject. He immediately asked Ed Schonberg to print out for me a copy of N. Wirth's Pascal compiler source code. This dive into the details of well-constructed source code was of great benefit. I also studied the lecture notes Jack had coauthored with John Cocke on compiler optimization, which has been an authoritative source of compiler techniques for a long while. I followed his early interests in the implementation of very high-level programming languages (SETL in his case, APL in mine) and concrete realization of parallelism (the ultra-computer and IBM's experimental RP3 shared memory MIMD computer in his case, and automatic parallelization of array-oriented programs in mine).

Jack had a strong interest in Chinese culture and civilization, and he clearly had spent time studying Chinese language and history. Jack told me that he had learned to read basic Chinese text on his own but had not learned to speak or write Chinese. He had remarkable insights into contemporary Chinese politics and their historical development. During the late 1960s and early 1970s, at the height of the Cultural Revolution, the conventional understanding of "progressive" intellectuals in the West about that upheaval in China, which was particularly brutal in its persecution of intellectuals, was that it represented Chairman Mao's last revolutionary effort to achieve a utopian society in China. Jack said this had nothing to do with pursuing an idealistic society but was simply a power struggle instigated by an old man who wanted to grab back total control from his comrades. Today Jack's understanding of the event is the consensus in China, although the official version of this period is vaguely referred to as Mao's mistakes in his old age. Jack was not ideological, but he said that Marx was simply a very angry man, not a founder of a "scientific" system, just as Karl Popper pointed out that what cannot be falsified is pseudo-science.

Jack gave a talk one evening around 1970 on major changes in Chinese civilization, sponsored by the New York Academy of Arts and Science, and asked me to attend. The theme of his talk was that the Mongols' rule of China (the Yuan dynasty lasted only ninety years) is an inflection point in Chinese history: it significantly brutalized Chinese civilization. As far as I know, Jack was the first one who clearly advanced this point of view, and it is a remarkable insight into the historical development of Chinese society. Indeed, there is a stark difference between the ways the emperors in the Song dynasty, which preceded the Yuang dynasty, and the Ming dynasty, which succeeded the Yuang dynasty, treated officials or subjects regarded as nonsubservient. The first emperor of the Ming dynasty, whom Mao admired, was extremely brutal in his purge of generals and officers who helped him establish his regime. A noted historian and vice-mayor of Beijing who wrote a critical biography of that emperor was thrown into jail at the start of the Cultural Revolution and died in prison. One is left to wonder how Jack could have had enough time to go through such a huge amount of material as to gain such a deep understanding of Chinese history-certainly not a scientific project!

Jack and I also discussed the great achievements of Chinese mathematicians before and after 1949 and those from mainland China, Taiwan, and Hong Kong. He remarked that for people from the same ethnic group, a less authoritarian environment had a better chance to produce outstanding mathematicians. He told me of the time he gave a talk to a group of high school students, and many of them asked him questions, with great confidence in themselves, oblivious to the fact that they were addressing a member of the National Academy of Sciences. In his opinion, only those young people who are not afraid of challenging authority would be able to produce original results in mathematics and science and the abundance of such young people is the strength of the United States.

\section{Paul M. Willig}

I came to Courant in 1963. By 1967 I had passed my orals and had been working for a while under Jack on group representations without making much progress. I have to give credit to my mother (not exactly in these words, but this gives the general

Paul M. Willig is former assistant professor of mathematics at the Stevens Institute of Technology. His email address is pandswi11ig@aol.com. 
idea) that I should go and talk to Jack about finding an area in which I could get my thesis done and get on with my life. I was encouraged by the fact that another student told me that he had had the same experience and that Jack had found a topic for him such as I was looking for.

As a result, I spoke to Jack, and he said that he would give the matter some thought. After a few days, he gave me his book on $W^{*}$-algebras to read and said he had some ideas for a thesis. I saw right away that this was a good fit, as it combined algebra and analysis, my two interests. After I read the book, Jack explained his ideas for a thesis. There is a general plan in studying mathematical objects to reduce their study to that of "simple" objects in some sense: for example, simple groups in group theory. In $W^{*}$-algebras the simple objects are called factors. Von Neumann wrote a major paper proving that any $W^{*}$-algebra can be represented as a direct integral of factors, a measure-theoretic concept. Jack's idea was to show that a $W^{*}$-algebra had a specific property if and only if all the factors in the decomposition had the same property. It is worth mentioning that Jack himself had recently contributed to advancing the state of knowledge about factors, the first advance in a number of years.

I got to work right away and wrote my thesis in a reasonable time. I left NYU in 1968 and went to teach at Stevens Institute of Technology. Jack was very accessible while I was working for him, although I must say that once he had explained his idea, I didn't need much further assistance. It turned out to be a good field for me, as I wrote (sometimes jointly) about a dozen papers over the next ten years.

After I completed my thesis, Jack remained interested in the subject of factors. He introduced me to Sal Anastasio, another former student of his, and encouraged us to write a monograph on recent work on factors. He not only suggested writing the book but also found us a second publisher after the first publisher we dealt with went bankrupt.

I would also like to mention one incident that took place while I was writing my thesis. I was taking a walk in the West Village on my lunch break and was thinking about something I was trying to prove. As a result, I walked right past Jack and some companions! Jack said "hello" and I apologized and told him that I had been "attacking gamma" (a property of some $W^{*}$-algebras). Jack said it sounded as though I was writing science fiction. He was not insulted and put me at ease with this quip.

I have only good feelings about working with Jack. Despite his great mathematical abilities and reputation, which could have led Jack to be conceited and aloof, he was a real and caring

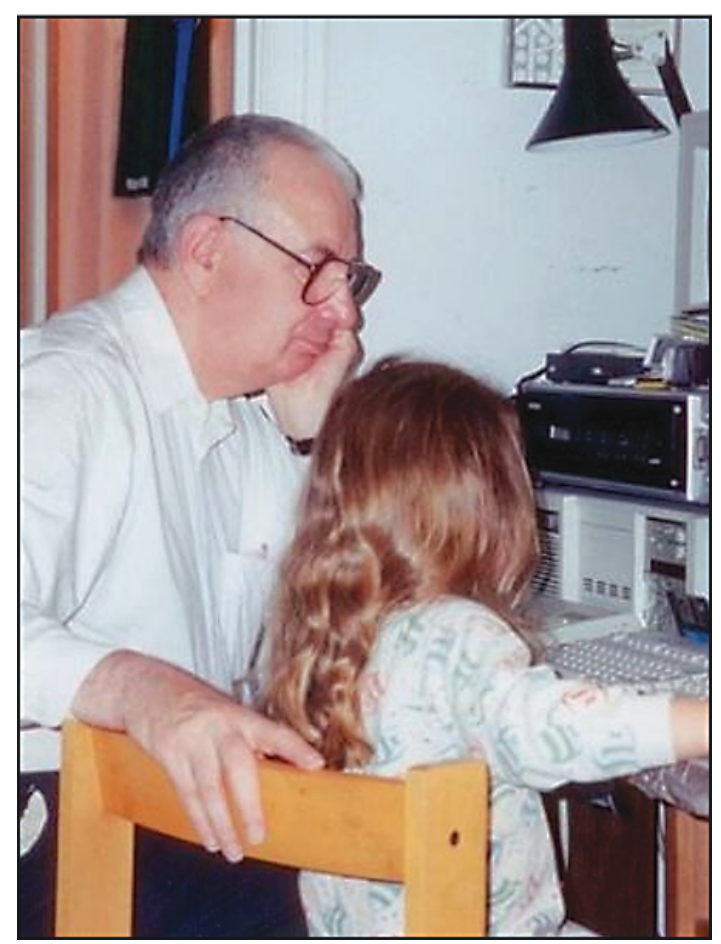

Jack and granddaughter, Adrienne Fainman, 1993. Photo taken by Diana Schwartz.

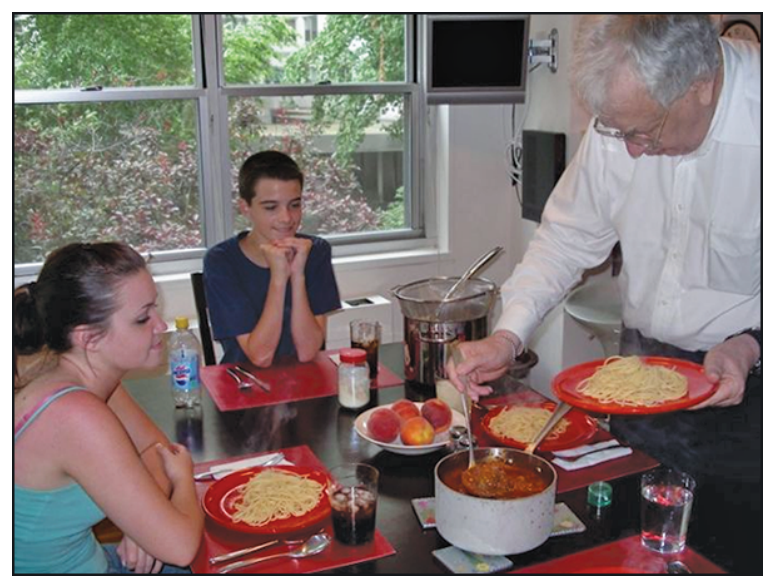

Jack serving his famous spaghetti to niece Rachael Robinson and nephew Jonathan Robinson. Photo taken by Diana Schwartz.

person who touched the lives of his students in many positive ways.

\section{References}

[1] S. ANASTASiO and P. Willig, The Structure of Factors, Algorithmic Press, NY, 1974. 


\section{Horacio Porta}

In the fall of 1963 I arrived at the Courant Institute as a nontypical first-year graduate student: I had already completed basic courses such as Measure Theory, Topology, Functional Analysis, Partial Differential Equations, etc., as requirements for my Licenciado en matemàtica at the Universidad de Buenos Aires. Consequently, I immediately enrolled in Lipman Bers's course in several complex variables and, most significantly, Nonlinear Functional Analysis with Jack Schwartz. A few weeks into the course, Jack proposed that Hector Fattorini, Ricardo Nirenberg, and I, close friends from our university days in Argentina, write up lecture notes for the course. These notes were produced by a combination of careful reflection and rocambolesque writing sessions. Jack reviewed our notes, and, little by little, a complete record of the course came into existence. We three had found it a wonderful experience to have a great mathematician be patient with unruly young beginners. Our hope was that our notes would preserve, in print, the outstanding clarity of Jack's verbal expositions. Our expectation was that these notes would be printed as Courant Institute Lecture Notes, but in fact they were ultimately published as the text Nonlinear Functional Analysis (Gordon \& Breach, 1969).

Meanwhile, Jack had indicated to me that he would be happy to be my thesis advisor. This sounded wonderful to me, but kind of scary. Of course, I accepted gratefully, and soon after Jack gave me reprints of his papers on factors in $W^{*}$-algebras and said, "See if you can continue this." I had studied all I thought I needed to know about $W^{*}$-algebras, but I couldn't add a word to his papers. When Powers gave the subject a big push, publishing what I was not clever enough to do, I knew this was not going to be my source of fame! But, no matter. One day, Jack gave me a sheet of paper with some results, adding that he had had the chance to work a little over the weekend and that I should see what I could do with it. After some study of his notes, I was able to add details and some corollaries, which met with his approval. He then gave me a few pointers to continue with, and eventually this became my thesis. Since the core of my work was what he had written on that single sheet of paper, we agreed, to my great pleasure, that we should publish it as a joint paper. I began preparing a draft, submitting it periodically to him for his scrutiny, and eventually it passed muster and was submitted to and eventually published in the Communications

Horacio Porta is professor emeritus of mathematics from the University of Illinois at Urbana-Champaign. His email address is hporta@icloud.com. of Pure and Applied Mathematics. Thus it became true that Jack Schwartz and I were coauthors of a joint paper. Although I had previously, while still in Argentina, published a paper on logic in the Compte Rendu, and had relished the experience of seeing my name in print, there was a special exhilaration in this case!

When my dissertation was accepted in the summer of 1966 and my $\mathrm{PhD}$ was conferred, it was time to look for a position. One day I bumped into "Gianco", Jack's first doctoral student, Gian Carlo Rota. He suggested that I apply to the University of Illinois in Urbana since Jacques Dixmier, one of the leading workers in the field of $W^{*}$-algebras, was going to be visiting there. I did so and they gave me a one-year non-tenure-track position as an instructor. Alas, however, the Milanese-Ecuadorian Rota had imprecise notions of American Midwest geography: Dixmier was in Indiana, not Urbana, and at Purdue, not Illinois! In 1989, still at Urbana, Jerry Uhl and I introduced a course called Calculus and Mathematica, which we wanted to make a clear, thorough, and correct source for the learning of calculus. We acknowledged that our approach had been strongly influenced by Jack Schwartz.

These lessons, the book Nonlinear Functional Analysis, and my joint paper with Jack gave me great joy to work on, and they stand in my memory at the top of the close to eighty publications that I am guilty of, all of which originated with or were influenced by Jack. I hope that some of these details will indicate his solicitude for and influence on his students and the generosity of his spirit.

\section{Sal Anastasio}

Although I was only a few years younger than Jack, I was his student. I came late to mathematics, not having studied calculus until I was twenty-four. After having taught high school mathematics for three years, I realized that I wanted to learn more mathematics and ultimately teach college students.

So, after a few years of part-time study, I was able, with the help of an NSF assistantship, to become a full-time student at the Courant Institute. When I took the oral comprehensive exams for the $\mathrm{PhD}$, Jack, known at that time mainly for his major contributions to analysis, was not on my analysis panel but on my algebra panel. (When Jerry Berkowitz was setting up my panels he asked me who had been my abstract algebra teacher. When I said, "Professor Schwartz," Jerry, obviously not expecting that answer, said, "Well, of course, Jack Schwartz knows everything.")

I passed the oral comprehensive exams, answering almost every question to the apparent satisfaction of the panel. But I came to realize later that they had not pushed me very hard, 
throwing only medium-speed fast balls at me-no tricky curves or sliders-whereas they sometimes pushed the top students to the limit, apparently having considered in advance that these students were shoo-ins. When Jerry Berkowitz told me I had passed, he added, "You should see Professor Schwartz about doing a thesis with him." Later on I surmised that perhaps the panels were a little dubious about me, but Jack, who had been my instructor in several courses and with whom I had participated in a seminar, may have said, "I know this guy, and I think he is worth working with."

Jack then gave me a problem in functional analysis to work on. After a few weeks, I realized that the problem was way beyond me. But before I could go to see him about it, he phoned me and said that he had a different problem for me, one in $W^{*}$ algebras. Shortly afterwards, James Glimm, visiting Courant at that time to work with Jack and others, "happened" to stop by the graduate assistants' room and suggested a certain area I might look into. Jack must have known me well enough that, given a push in the right direction, I would be able to carry the ball on my own, which I did, in good time with virtually no further assistance. (Whenever I would show him a preliminary result and its proof, before reading the proof he would say, "Oh sure, that kind of result has to be true." And, incidentally, in 1963-64, whenever I stopped by his office he would be immersed in books about the vision of cats-he was apparently thinking of pattern recognition.)

While completing my thesis, I spoke to Jack about postdoctoral plans. I said that I understood that to be a success I should look for a research fellowship, but what I really wanted to do was to find a college teaching position. He said, "Sal, there are many successes." So off I went to a forty-year career as a college teacher. My entire research output during that long expanse was three papers and, with Paul Willig, another of Jack's students, a short book suggested to us by Jack as a sequel to his own text on $W^{*}$-algebras.

It is worth commenting on this book. Jack suggested to Paul and me that we collate the flurry of new results in $W^{*}$-algebras which had appeared since his text had been published, presenting them in a coherent way, tying up the loose ends. In Jack's seminar he had re-proved one of the major new results in a simpler way. He gave us these notes and permission to include them in our book. Not only did he motivate us, but he arranged with a friend of his who was opening a new press devoted to science and mathematics to have it published. At my college forty years ago, the publication of that book was a great asset in my promotion to professor.

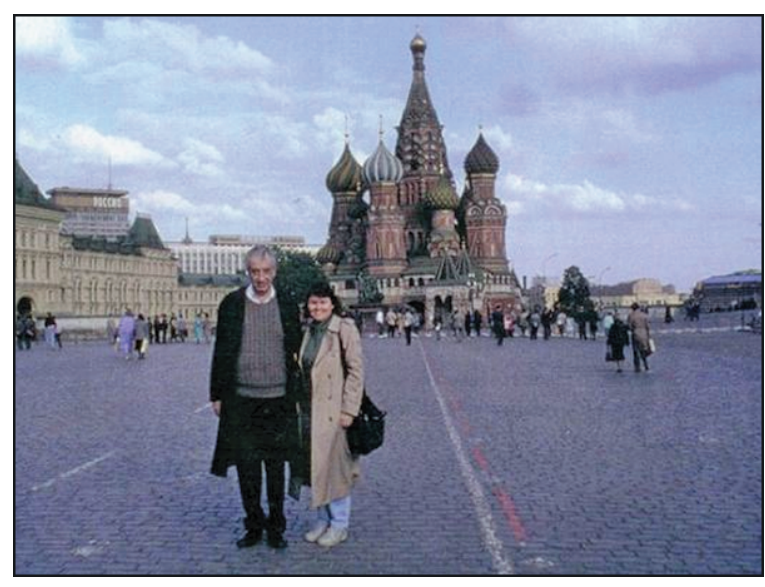

Jack and wife, Diana, in Red Square, Moscow, 1990. Photo taken by Nikita Vvedenskaya.

Now to the heart of this tribute to Jack. For the last twenty years or so of my teaching career, I was particularly involved with teaching and advising prospective high school mathematics teachers and active high school teachers pursuing an MS in Ed degree. Meanwhile, my wife was the director of one of the New York State "Teacher Centers" (housed on the SUNY-New Paltz campus, but responsible for several neighboring counties). In her work she came into contact with many mathematics teachers in neighboring high schools. They told her that I was an excellent teacher, that I had made a great difference in their own mathematical training, and that they tried to imitate my teaching methods in their own teaching. So, although it is quite clear that I was not much of a researcher, it appears that I was a good teacher of mathematics teachers. It then occurred to me: "I must write to Jack. If it had not been for him, I might well not have been in a position to influence so many high school teachers. I should let him know that I believed that, thanks to him, the quality of mathematics teaching in and around the Hudson Valley was raised a notch or two." I think he would have considered this one of his "many successes." Sadly, I never wrote that letter. This, then, is a belated tribute and expression of gratitude.

Finally, I would like to recount two episodes, the first of which is quintessential Jack Schwartz and the second an example of his scientific prescience.

In her lovely reminiscence of Jack given at his Courant memorial, his sister, Judith, spoke of how Jack seemed to think that everyone, she in particular, was capable of doing what he could do. I experienced this myself in the mid-1970s when I had a sabbatical and spent a few days a week at Courant. Along with what turned out to be a futile attempt to "get back into research," I decided to learn some computer science. Accordingly, I 


\section{World Scientific}

Connecting Great Minds

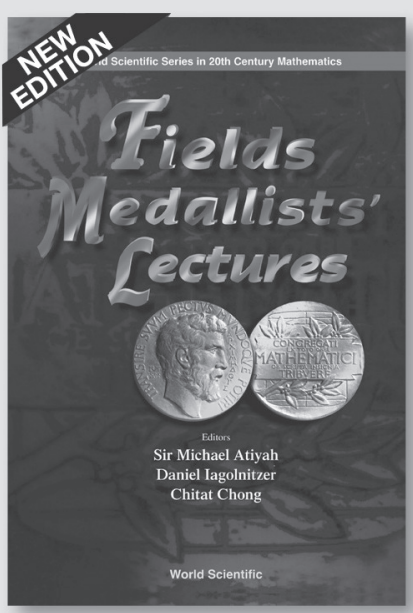

World Scientific Series in 20th Century Mathematics

\section{Fields Medallists' Lectures 3rd Edition}

Edited by: Sir Michael Atiyah (University of Edinburgh, UK), Daniel lagolnitzer (CEA-Saclay, France), Chitat Chong (NUS, Singapore)

A list of Fields Medallists and their contributions provides a bird's-eye view of the major developments in mathematics over the past 80 years. It highlights the areas in which, at various times, the greatest progress was made.

Readership: Mathematicians and mathematical physicists.

Oct 2015

978-981-4696-17-3

978-981-4696-18-0(pbk)

US\$96

US\$58

\section{Journal of Mathematical Logic (JML)}

OURNAL O Mathematical LOGIC

Managing Editors

Chitat Chong (NUS, Singapore)

Qi Feng (Chinese Academy of

Sciences, China)

Theodore A Slaman

(UC Berkeley, USA)

W Hugh Woodin

(Harvard University, USA)

FREE sample issue available @ www.worldscinet.com/jml

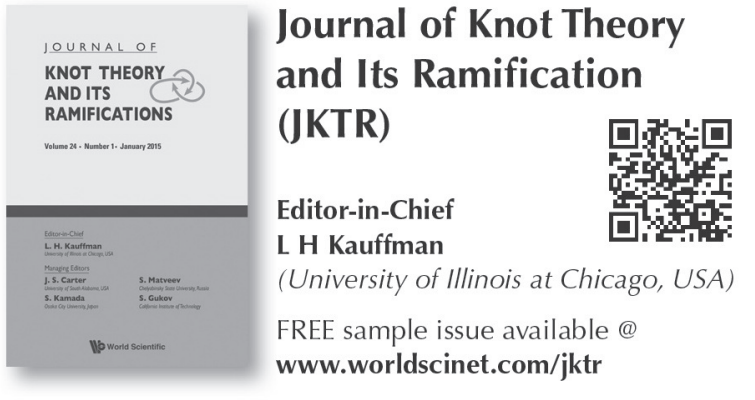

taught myself FORTRAN over the summer and then planned to attend a few courses in computer science. When I spoke to Jack of my plans, he immediately suggested a project for me. One of his $\mathrm{PhD}$ students in computer science had recently finished a 700-page thesis on parsing algorithms. Jack said it could be a valuable resource for students if it were made more "user friendly" and, "Sal, since you are good at exposition, why don't you take it and see what you can do with it." Remember, I knew less about computer science than a student out of Comp Sci 101. I had never heard the phrase "parsing algorithms." After preparing myself for the project by reading a fundamental text on the subject and beginning to read the thesis, I suggested to Jack that adding some examples would be helpful. Jack's response: “Well, OK, but I don't find examples helpful myself-they just get in the way." In the end I learned a bit about parsing algorithms but never got beyond the first eighty pages of the thesis.

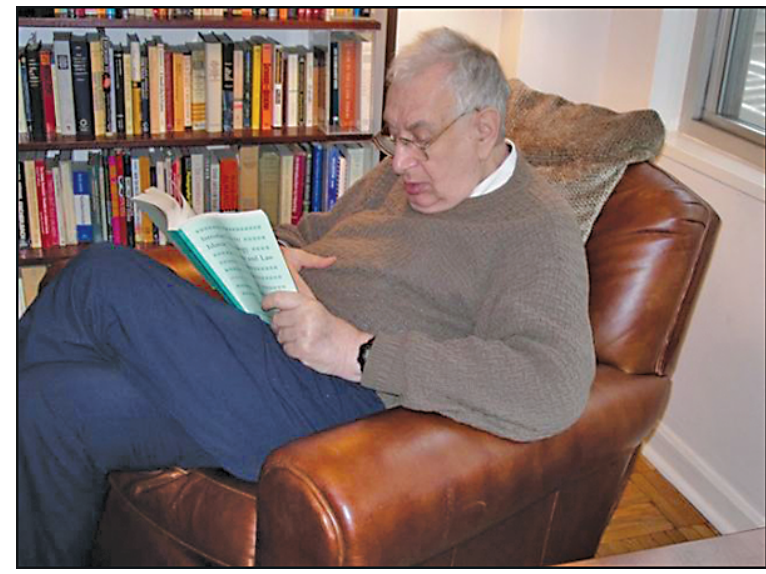

Jack's favorite reading chair, 70 East 10th Street, NYC, 2007. Photo taken by Diana Schwartz.

As to his scientific prescience: In 1963 I was Jack's assistant in a survey course for high school mathematics teachers. Among the topics he treated was an introduction to computers. The Courant Institute had a CDC computer, one of the biggest and fastest in the world at that time. It took up most of the second floor of the mathematics building. When he concluded his last lecture on the topic, Jack said to the class, "I predict that in your lifetime you will see a computer, better and faster than our CDC - and it will fit in a shoebox." 